\title{
Chromosomal location of genes for hydroxamic acid accumulation in Triticum aestivum L. (wheat) using wheat aneuploids and wheat substitution lines
}

\author{
HERMANN M. NIEMEYER* \& JOSÉ M. JEREZ \\ Departamento de Ciencias Ecológicas, Facultad de Ciencias, Universidad de Chile, Casilla 653, Santiago, Chile
}

\begin{abstract}
Hydroxamic acids are defensive secondary metabolites in wheat, the most abundant aglucones being DIMBOA and DIBOA. The location of genes coding for the accumulation of hydroxamic acids by wheat (Triticum aestivum L.) seedlings was explored comparing the euploid of cultivar Chinese Spring with aneuploids of the same cultivar, and substitution lines of cultivar Chinese Spring with cultivar Cheyenne. Significant differences in DIBOA and DIMBOA concentrations in young seedlings with respect to the euploid $\left(0.08\right.$ and $5.9 \mathrm{mmol} \mathrm{kg}^{-1}$ fresh weight, respectively) were found in the following lines: monosomic lines 4A (3.9 and 2.8) and 5B (0.29 and 2.7), substitution line 4A (1.7 and 3.2) and nulli/tetra lines N4AT4B (0.39 and 7.0), N4AT4D (0.20 and 0.48), N5BT5A (0.12 and 0.34) and N5BT5D (0.06 and 0.63). These results suggest the involvement of chromosomes of group 4 and also chromosome $5 \mathrm{~B}$ in the accumulation of hydroxamic acids in wheat seedlings.
\end{abstract}

Keywords: DIMBOA, hydroxamic acids, wheat.

\section{Introduction}

Hydroxamic acids $(\mathrm{Hx})$ are a family of secondary metabolites of cereals discovered over three decades ago in relation to the resistance of rye to fungal diseases (Niemeyer \& Pérez, 1995). They are present in wheat and maize, as well as in a wide range of wild Gramineae (Niemeyer, 1988a,b; Niemeyer et al., 1992). Hx exist in the intact plant as glucosides that, upon injury to the plant tissue, are transformed to the more toxic aglucones by an endo$\beta$-glucosidase (Hofman \& Hofmanova, 1969; Cuevas et al., 1992). In wheat extracts, the most abundant aglucone is 2,4-dihydroxy-7-methoxy-1,4-benzoxazin3-one (DIMBOA), whereas its demethoxylated analogue, DIBOA, is a minor constituent (Niemeyer, 1988a).

Two different ways of producing DIMBOA aglucone have been reported: synthesis via the methoxylated lactam, supported by time-course studies of the incorporation of radiolabel from putative precursors into Hx in maize seedlings (Tipton et al., 1973), and synthesis from DIBOA, supported by time-course

\footnotetext{
*Correspondence. E-mail: niemeyer@abulafia.ciencias.uchile.cl
}

studies of the accumulation of $\mathrm{Hx}$ in wheat callus cultures (Zúñiga et al. 1990) (Fig. 1). The hydroxamic acid aglucones are further transformed into glucosides for storage (Leighton et al. 1994).

Several lines of argument point to the potential usefulness of $\mathrm{Hx}$ in developing wheat cultivars resistant to aphids, a major cereals pest worldwide: (i) $\mathrm{Hx}$ are capable of reducing cereal aphid populations through antibiosis (Argandoña et al. 1980) and antixenosis (Nicol et al. 1992; Givovich \& Niemeyer 1995), and of decreasing infection of wheat by barley yellow dwarf virus through deterrence of aphid feeding (Givovich \& Niemeyer 1991); (ii) the developmental time of the aphid-predatory ladybird Eriopis connexa (Germar) is shorter, and the number of aphids ingested higher, when the beetle feeds on aphids from a high-Hx wheat cultivar compared with an intermediate-Hx cultivar (Martos et al. 1992), suggesting that higher $\mathrm{Hx}$ levels in wheat could promote the beneficial effects of the predator; (iii) sublethal doses of insecticide are more effective on aphids feeding on a high-Hx wheat cultivar than on a low one (Nicol et al. 1993); and (iv) increased levels of $\mathrm{Hx}$ do not involve a yield penalty in fieldgrown wheat (Gianoli et al. 1996). 


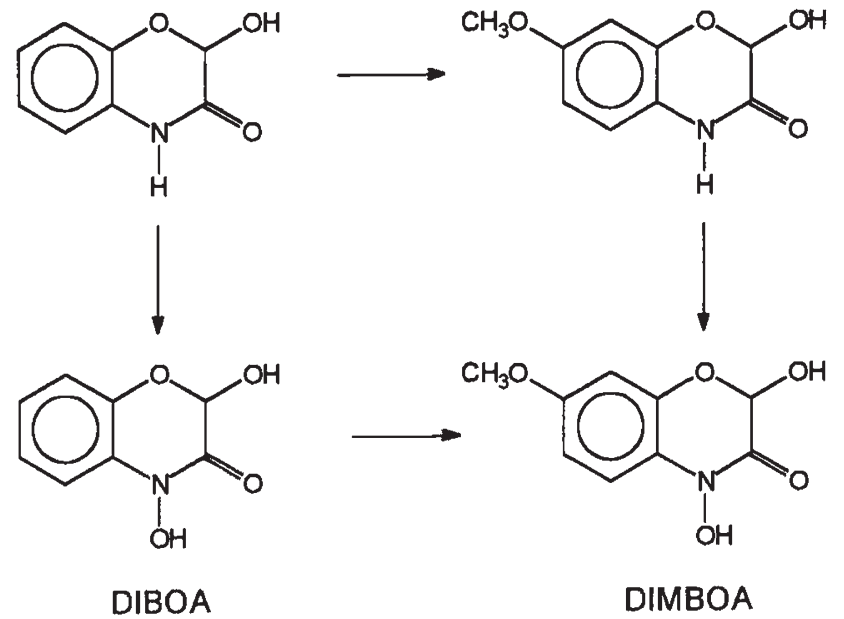

Fig. 1 Possible biosynthetic pathways leading to the production of DIMBOA in cereals.

Efficient breeding of wheat for higher levels of hydroxamic acids may benefit from knowledge of the chromosomal location of genes coding for their accumulation. In this paper, we explore this location using wheat aneuploids and substitution lines.

\section{Materials and methods}

Seeds were obtained from the University of Missouri (monosomic lines of hexaploid wheat Triticum aestivum L. cv. Chinese Spring) or from the AFRC Institute of Plant Science Research (substitution lines of T. aestivum cv. Cheyenne into cv. Chinese Spring, and nullisomic/tetrasomic lines of $T$. aestivum cv. Chinese Spring). Seeds were sown individually in $5-\mathrm{cm}$ diameter pots containing vermiculite and kept in a plant growth chamber at $20^{\circ} \mathrm{C}, 60$ per cent relative humidity, with a 12 -h photophase. Five days after planting, seedlings in decimal growth stage 10 (Zadoks et al. 1974) were harvested. Fresh material was weighed and the aqueous extracts produced were subjected to high-performance liquid chromatography on a reversed-phase column, as described previously (Niemeyer et al. 1989). The aerial part of one seedling constituted one replicate; a variable number of replicates, up to 10 , was analysed from each line. Significant differences between wheat lines analysed were determined by ANOVA $(P<0.05)$ and the multiple comparisons between mean values of $\mathrm{Hx}$ concentrations were made using the Tukey test.

Karyotypes were not determined for each of the seedlings analysed. Segregation of monosomic lines is expected to lead to about 75 per cent monosomic and 25 per cent disomic seedlings.

\section{Results and discussion}

The basis for these studies was the hexaploid wheat cultivar Chinese Spring. This cultivar has been the subject of extensive genetic studies and also showed a high concentration of DIMBOA at the seedling stage $\left(5.9 \mathrm{mmol} \mathrm{kg}^{-1}\right.$ fresh weight). Analysis of Chinese Spring monosomic lines is shown in Fig. 2. Significant differences in $\mathrm{Hx}$ concentrations were obtained when either chromosome $4 \mathrm{~A}$ or $5 \mathrm{~B}$ was absent, suggesting a dosage effect and the presence in these chromosomes of genes involved in $\mathrm{Hx}$ accumulation.

The significantly lower concentration of DIMBOA and higher concentration of DIBOA in monosomic line $4 \mathrm{~A}$ compared with the euploid suggests that this chromosome contains a gene(s) involved in the transformation of DIBOA into DIMBOA. The fact that T. urartu, the putative donor of genome $\mathrm{A}$ of hexaploid wheat, accumulates DIBOA but not DIMBOA further suggests this gene(s) is not present in the diploid genome. One possibility is that the gene(s) may have been introduced into genome $\mathrm{A}$ of the hexaploid through translocations from a homoeologous chromosome, most probably chromosome 4B, as $T$. tauschii, the putative donor of genome $\mathrm{D}$ of hexaploid wheat, does not accumulate DIMBOA to any substantial extent, whereas $T$. speltoides, the putative donor of genome $\mathrm{B}$ of hexaploid wheat, accumulates DIMBOA in substantial amounts (Niemeyer et al. 1992). However, numerous restriction fragment length polymorphism (RFLP) studies have failed to show the occurrence of translocations between chromosomes $4 \mathrm{~A}$ and $4 \mathrm{~B}$. Alternatively, the differential accumulation of DIBOA in the $4 \mathrm{~A}$ monosomic line may result from compensation by gene(s) of other chromosomes, probably chromosome $4 \mathrm{~B}$, for the reasons just given.

The nulli/tetra line, CS-N4AT4B, accumulates high concentrations of DIMBOA with hardly any accumulation of DIBOA (Table 1), suggesting that chromosome $4 \mathrm{~B}$ is able to compensate for the absence of $4 \mathrm{~A}$ and, hence, that $4 \mathrm{~B}$ may also contain a locus for the transformation of DIBOA into DIMBOA, providing support for the compensation hypothesized earlier. It is not clear, however, why monosomic line 4B accumulates hydroxamic acids in concentrations similar to the cultivar.

A comparison of the $\mathrm{Hx}$ levels in tetraploid wheats with genome $\mathrm{AABB}$ and hexaploid wheat with genome $\mathrm{AABBDD}$ shows that the incorpora- 
Fig. 2 Hydroxamic acid (Hx) concentrations in monosomic lines of Chinese Spring wheat (Triticum aestivum L.). Bars represent mean Hx values. Means sharing a letter are not significantly different $(P>0.05$, Tukey test).

Fig. 3 Hydroxamic acid (Hx) concentrations in substitution lines of wheat (Triticum aestivum L.) cultivar Chinese Spring with wheat cultivar Cheyenne. Bars represent mean $\mathrm{Hx}$ values. Means sharing a letter are not significantly different $(P>0.05$, Tukey test).
DIBOA

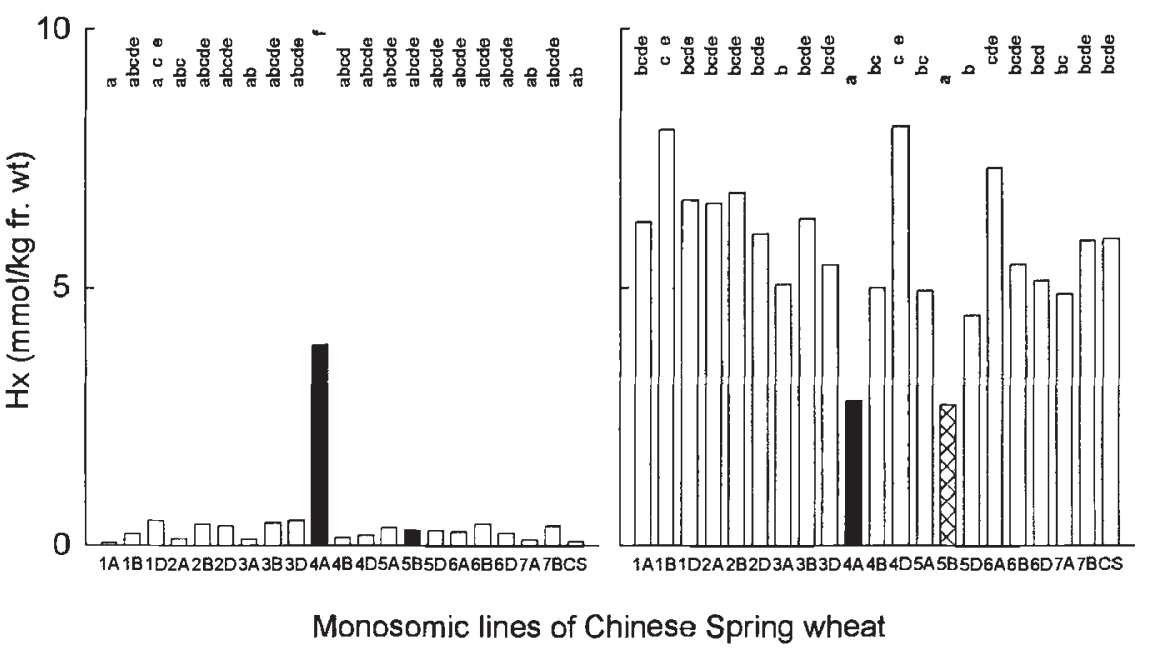

DIBOA

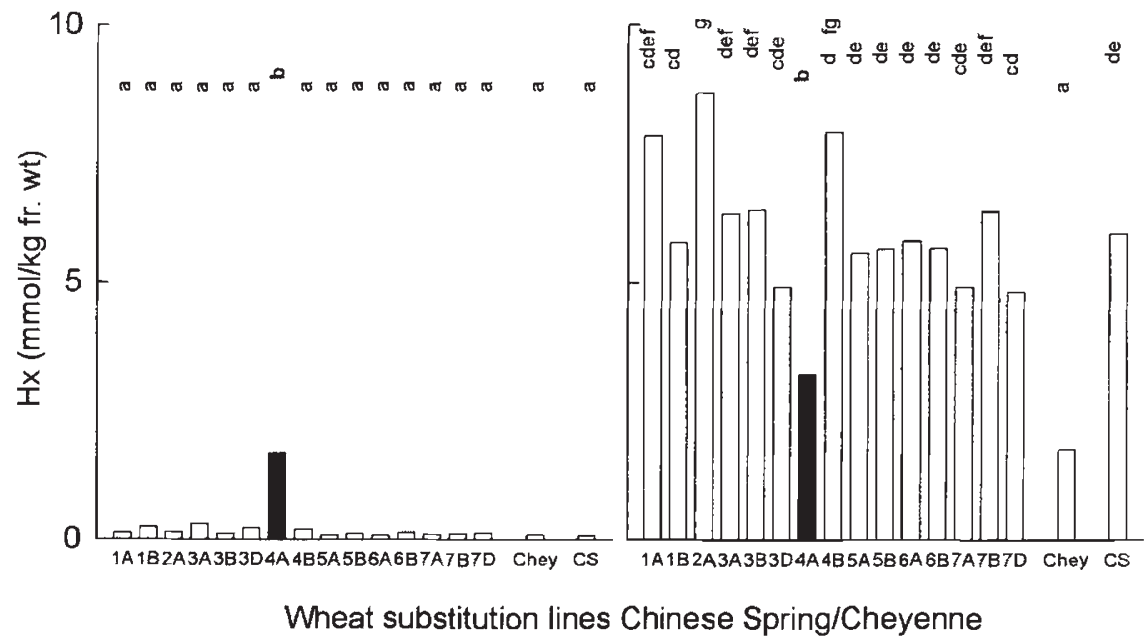

Table 1 Hydroxamic acids in nullisomic/tetrasomic lines of wheat cultivar Chinese Spring

\begin{tabular}{lccc}
\hline & & \multicolumn{1}{c}{ Hydroxamic acids (mmol kg } & \\
\cline { 3 - 4 } Genome & $n$ & DIBOA & DIMBOA \\
\hline Chinese Spring & 10 & $0.08 \pm 0.023$ & $5.9 \pm 2.0$ \\
CS-N4AT4B & 5 & $0.39 \pm 0.20$ & $7.0 \pm 3.4$ \\
CS-N4AT4D & 1 & 0.20 & 0.48 \\
CS-N5BT5A & 4 & $0.12 \pm 0.12$ & $0.34 \pm 0.60$ \\
CS-N5BT5D & 4 & $0.06 \pm 0.04$ & $0.63 \pm 0.69$ \\
\hline
\end{tabular}


tion of genome $\mathrm{D}$ leads to a considerable decrease in $\mathrm{Hx}$ accumulation (Niemeyer 1988b). The low concentrations of both DIBOA and DIMBOA in the nulli/tetra line, CS-N4AT4D (Table 1), is consistent with this and suggests the presence in chromosome $4 \mathrm{D}$ of a gene inhibiting the accumulation of $\mathrm{Hx}$.

In the case of monosomic line 5B, the significant decrease in DIMBOA with no significant change in DIBOA with respect to the cultivar suggests the presence in chromosome $5 \mathrm{~B}$ of genes coding for a pathway producing DIMBOA without the involvement of DIBOA, presumably through the methoxylated lactam (Fig. 1). Thus, when this chromosome is present in reduced proportion, as in the monosomic line $5 \mathrm{~B}$, less DIMBOA is produced without a concomitant increase in DIBOA concentration. The suggestion is supported by results from the analysis of nulli/tetra lines, CS-N5BT5A and CS-N5BT5D, in which replacement of $5 \mathrm{~B}$ chromosomes by either $5 \mathrm{~A}$ or $5 \mathrm{D}$ led to lines that accumulate very small concentrations of DIMBOA and DIBOA.

A screening was performed of different wheat cultivars for which substitution lines with Chinese Spring were available, to search for one showing particularly low levels of $\mathrm{Hx}$. The cultivar selected was Cheyenne, which showed only $1.2 \mathrm{mmol} / \mathrm{kg}$ fresh weight of DIMBOA at the seedling stage. Results from the analysis of substitution lines of Chinese Spring with Cheyenne, shown in Fig. 3, are consistent with those of Fig. 2, in that substitution of chromosome 4A leads to a decrease in DIMBOA accumulation and an increase in DIBOA accumulation with respect to other substitution lines. Surprisingly, no significant effect was shown by chromosome $5 \mathrm{~B}$.

In summary, the results of this study suggest a multigenic control of the accumulation of hydroxamic acids in wheat involving chromosomes $4 \mathrm{~A}, 4 \mathrm{~B}$, $4 \mathrm{D}$ and $5 \mathrm{~B}$.

\section{Acknowledgements}

This work was funded by grants from the International Program in the Chemical Sciences of Uppsala University (IPICS), the Swedish Department of Research Cooperation (sida - SAREC) and the Commission of European Communities (contract CII*-CT91-0946). The authors are indebted to Professor G. Kimber and Drs C.N. Law, T.E. Miller and A.M. Castro for the seeds employed in this study, to Mrs S.V. Copaja and $\mathrm{Mr} \mathrm{H}$. Collantes for part of the analytical work, and to two anonymous referees for suggestions that improved the quality of the manuscript.

\section{References}

ARGANDOÑA, V. H., LUZA, J. G., NIEMEYER, H. M. AND CORCUERA, L. J. 1980. Role of hydroxamic acids in the resistance of cereals to aphids. Phytochemistry, 19, 1665-1668.

CUEVAs, L., NIEMEYER, H. M. AND JONSSON, L. M. V. 1992. Partial purification and characterization of a hydroxamic acid glucoside $\beta$-D-glucosidase from maize. Phytochemistry, 31, 2609-2612.

GlANOL1, E., PAPP, M. AND. NIEMEYER, H. M. 1996. Costs and benefits of hydroxamic acids-related resistance of winter wheat against the bird cherry-oat aphid of hydroxamic acids-related resistance of winter wheat against the bird cherry-oat aphid, Rhopalosiphum padi, L. Ann. appl. Biol., 129, 83-90.

GIVOVICH, A. AND NIEMEYER, H. M. 1991. Hydroxamic acids affecting barley yellow dwarf virus transmission by the aphid Rhopalosiphum padi. Entomologia exp. appl., 59, 79-85.

Glvovich, A. AND NiEMEYER, H. M. 1995. Comparison of the effect of hydroxamic acids from wheat on five species of cereal aphids. Entomol. exp. appl., 74, $115-119$.

HOFMAN, J. AND HOFMANOVA, O. 1969. 1,4-Benzoxazine derivatives in plants. Sephadex fractionation and identification of a new glucoside. Eur. J. Biochem., 8, 109-112.

LElGHTON, V., NIEMEYER, H. M. AND JONSSON, L. M. V. 1994. Substrate specificity of a glucosyltransferase and an $\mathrm{N}$-hydroxylase involved in the biosynthesis of cyclic hydroxamic acids in Gramineae. Phytochemistry, 36, 887-892.

MARTOS, A., GIVOVICH, A. AND NIEMEYER, H. M. 1992. Effect of DIMBOA, an aphid resistance factor in wheat, on the aphid predator Eriopis connexa Germar (Coleoptera: Coccinellidae). J. Chem. Ecol., 18, 469-479.

NiCOL, D., COPAJA, S. V., WRATTEN, S. D. AND NIEMEYER, H. M. 1992. A screen of worldwide wheat cultivars for hydroxamic acid levels and aphid antixenosis. Ann. appl. Biol., 121, 11-18.

NICOL, D., EATON, N., WRATTEN, S. D. AND COPAJA, S. V. 1993. Effects of DIMBOA levels in wheat on the susceptibility of the grain aphid (Sitobion avenae) to deltamethrin. Ann. appl. Biol., 122, 427-433.

NIEMEYER, H. M. 1988a. Hydroxamic acids (4-hydroxy-1, 4-benzoxazin-3-ones), defence chemicals in the Gramineae. Phytochemistry, 27, 3349-3358.

NIEMEYER, H. M. 1988 b. Hydroxamic acid content of Triticum species. Euphytica, 37, 289-293.

NIEMEYER, H. M. AND PÉREZ, F. J. 1995. Potential of hydroxamic acids in the control of cereal pests, diseases, and weeds In Inderjit, Dakshini, K. M. N. and Einhellig, F. A. (eds) Allelopathy. Organisms, Processes, and Applications. ACS Symposium Series 582, pp. 260-270. American Chemical Society, Washington, DC. NIEMEYER, H. M., PESEl, E., COPAJA, S. V., BRAVO, H. R., FRANKE, S. AND FRANCKE, w. 1989. Changes in hydroxa- 
mic acid levels of wheat plants induced by aphid feeding. Phytochemistry, 26, 447-449.

NIEMEYER, H. M., COPAJA, S. V. AND BARRÍA, B. N. 1992. The Triticeae as sources of hydroxamic acids, secondary metabolites in wheat conferring resistance against aphids. Hereditas, 116, 295-299.

TIPTON, C. I., WANG, M.-C., TSAO, F. H.-C. AND LIN TU, C.-C. AND HUSTED, R. R. 1973. Biosynthesis of 1, 4-benzox- azin-3-ones in Zea mays. Phytochemistry, 12, 347-352.

ZADOKS, J. C., CHANG, T. T. AND KONSAK, C. F. 1974. A decimal code for the growth stage of cereals. Weed Res., 14, 415-421.

ZÚNIGA, G. E., COPAJA, S. V., BRAVO, H. R. AND ARGANDOÑA, V. H. 1990. Hydroxamic acids accumulation by wheat callus. Phytochemistry, 29, 2139-2141. 